\title{
Variation in skull size and shape of the Common wall lizard (Podarcis muralis): allometric and non-allometric shape changes
}

\author{
Aleksandar Urošević ${ }^{1,3}$, Katarina Ljubisavljević ${ }^{1}$, Ana Ivanović ${ }^{2}$ \\ ${ }^{1}$ Department of Evolutionary Biology, Institute for Biological Research 'Siniša Stanković', University of Belgrade, \\ Bulevar Despota Stefana 142, 11060, Belgrade, Serbia \\ ${ }^{2}$ Institute of Zoology, Faculty of Biology, University of Belgrade, Studentski trg 16, 11000 Belgrade, Serbia \\ ${ }^{3}$ E-mail: aurosevic@ibiss.bg.ac.rs
}

Key words: cranial skeleton, insularity, lacertid lizards, syntopy

\begin{abstract}
We analysed patterns of skull size and shape variation among populations of the Common wall lizard (Podarcis muralis) in the Central Balkans, particularly the effecs of insularity and the presence of the ecologically similar lacertid lizard species $P$. melisellensis. Two components of shape variation were analysed - size dependent (allometric) and size independent shape changes. The observed shape differentiation relating to insularity was greatly size-dependent and concordant to allometric shape changes which explained over $20 \%$ of variation in the skull shape in the analysed sample. The explorative analysis of size-independent shape changes revealed that populations of $P$. muralis which share habitat with $P$. melisellensis diverge from populations which do not share habitat with potentially competing species. These changes related to the general shortening and widening of the skull and increase of the jaw adductor muscle chambers were more pronounced in males. We suppose that the observed pattern of shape changes is driven by competition among species (character displacement) and, possibly, is further modified by heterospecific aggression and trophic shift.
\end{abstract}

\section{Contents}

Introduction 67

Material and methods ................................................................... 68

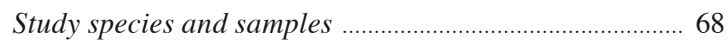

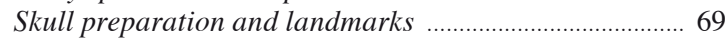

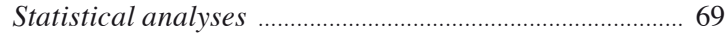

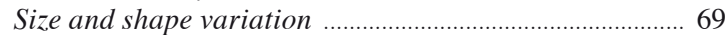

Analysis of allometry and removing the effect of size .... 69

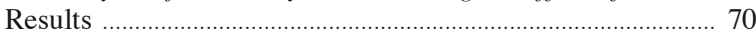

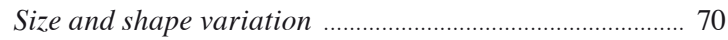

Analysis of allometry and removing the effect of size .... 73

Discussion ........................................................................... 73

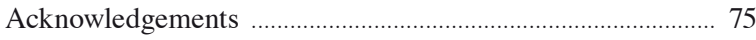

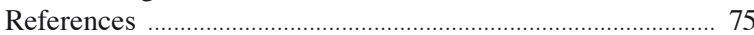

\section{Introduction}

Intraspecific variation in body size and shape results from numerous intrinsic and extrinsic factors that in- teract to drive patterns of phenotypic variation (Hallgrímsson and Hall, 2005). The variation in body shape per se is composed of two components: allometric and non-allometric shape components. Allometry is the shape change associated with size variation (i.e., Gould, 1966), while the non-allometric component accounts for the changes in shape which are not simply a result of biological scaling, but are influenced by other factors and selective pressures (Klingenberg, 1996). Despite growing use of size-correction in morphology, studies on the separated allometric and non-allometric components of the intraspecific shape variation are relatively rare (Debat et al., 2003; Gidaszewski et al., 2009; Ljubisavljević et al., 2010; Singleton et al., 2011).

Numerous empirical studies on intraspecific morphological variation found that diversification in size and shape within species can arise via ecological character displacement due to interspecific competition (Brown and Willson, 1956; Pianka, 1973; Arnold, 1987; Losos, 2000; Schluter, 2000; Adams and Collyer, 2007; Stuart and Losos, 2013), different resource availability and environmental factors in habitats (e.g., Meiri et al., 2011), heterospecific aggressive interactions (Schoener, 1977) or phenotypic plasticity alone (Pfenning et al., 2010). The most pronounced pattern of intraspecific variation in size in vertebrates could be related to the 'island rule', (Foster, 1964; Carlquist, 1965; Van Valen, 1973; Case, 1978; Pearson et al., 2002; Lomolino, 2005; but see also Meiri et al., 2006, 2008; Meiri, 2007).

In this study, we analysed patterns of variation in skull size and skull shape of the Common wall lizard (Podarcis muralis (Laurenti, 1768)) among insular and mainland populations in the Central Balkans region (Serbia and Montenegro). Because insular gigantism was confirmed in wall lizards of the genus Podarcis (Radovanović, 1951; Cirer and Martínez-Rica, 1990; Crnobrnja et al., 1994; Castilla et al., 1998; Sá-Sousa 
et al., 2000; Arnold and Ovenden, 2002; Arntzen and Sá-Sousa, 2007; Herrel et al., 2008) we assumed that differences in size and shape between insular and mainland populations of Podarcis muralis could account for most of the size related variation in this species. We also explored and compared the populations from the same geographic region (Skadar Lake) in which Podarcis muralis is the sole lacertid species with the populations in which $P$. muralis co-occurs with the morphologically and ecologically similar species Podarcis melisellensis (Braun, 1877).

Populations of the common wall lizard from the Central Balkans are very suitable for such kind of study due to low levels of genetic differentiation (Crnobrnja et al., 1994). Using landbridge island populations of the Skadar Lake archipelago which are of relatively recent, postglacial origin (Stanković, 1976), it was ensured that only closely related genetic lineages are used and the effect of island age is minimized (Meiri, 2007).

The size and shape of the ventral part of the skull (upper jaw and palate) of lacertid lizards has proven to be a good model-system for ecomorphological and evolutionary studies due to its biomechanical roles related to foraging, diet, mating, anti-predatory behaviour and shelter use (Herrel et al., 2007; Ljubisavljević et al., 2010, 2011; Urošević et al., 2012, 2013). By using the geometric morphometric approach (Zelditch et al., 2012) we captured variation in ventral skull size and shape and we disentangled the allometric and non-allometric components of skull shape variation to assess whether shape changes among populations are attributable to change in size, or influenced by other sources of variation.

\section{Material and methods}

\section{Study species and samples}

Podarcis muralis is a small, insectivorous, saxicolous lizard which is found over a wide range in central and southern Europe (Arnold and Ovenden, 2002) including the Central Balkans.

The samples of $P$. muralis from two islands and northern shore of the Skadar Lake (Malo Starčevo island: 17 males and 20 females; Malo Beško island: 15 males and 15 females, shore locality of Zeta: 14 males and 15 females) and urban and sub-urban localities in Belgrade, Serbia (23 males and 25 females) were initially collected for other studies. All specimens were adults, which was determined by dissection and inspection of gonads.

In the Belgrade (mainland) and Malo Starčevo (island) habitats, P. muralis is the sole Podarcis species. Populations from the Zeta (mainland) and Malo Beško (island) share their habitat with $P$. melisellensis. In places where the two species occur in the same habitat, $P$. melisellensis is more terrestrial than P. muralis and opts for horizontal, vegetated microhabitats (Džukić, 1977; Arnold, 1987; Aleksić et al., 2009). More detailed information on the samples and localities was published earlier (Bejaković et al., 1996; Aleksić et al., 2009; Urošević et al., 2012). In the remainder of this paper, the populations in which $P$. muralis co-occurs with $P$. melisellensis are referred to as syntopic.

All specimens were deposited in the Herpetological Collections of the Institute for Biological Research 'Siniša Stanković', University of Belgrade, Serbia. De-

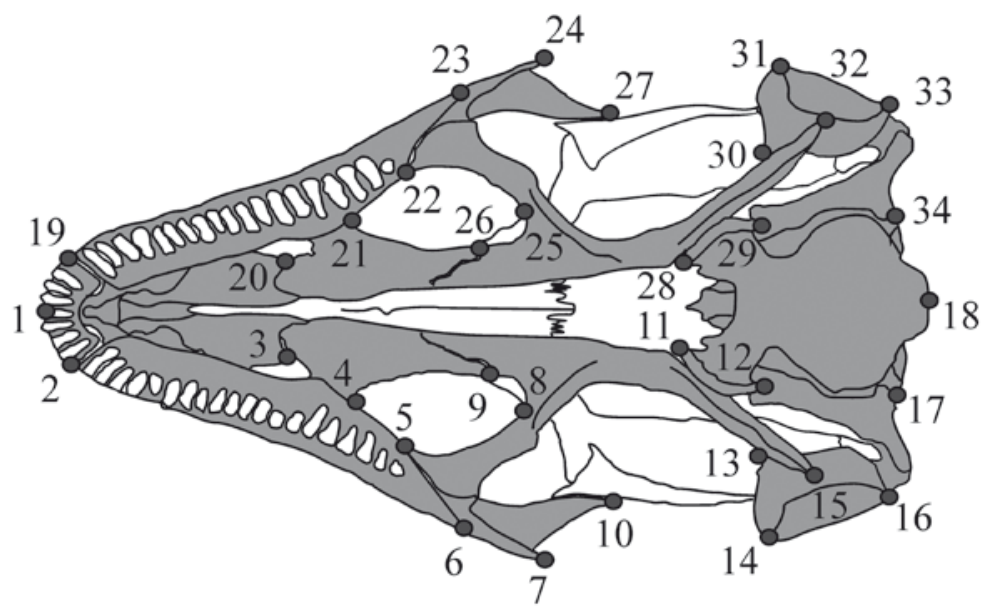

Fig. 1. Landmarks on the ventral side of the skull: 1 - Tip of premaxilla (tip of the snout); 2 , 19 - Suture between premaxilla and maxilla; 3 , 20 - Suture between vomer and palatine; 4, 21 Anteriormost point of subocular foramen; 5, 22 - Anteriormost point of ectopterygoid; 6, 23 Posterior tip of maxilla; 7, 24 - Lateralmost point of skull; 8, 25 - Posteriormost point of subocular foramen; 9, 26 - Suture between pterygoid and palatine; 10, 27 - Posterior tip of jugal; 11, 28 - Anterior tip of basipterygoid process; 12, 29 - Posterior tip of basipterygoid process; 13, 30 - Anteriormost point of quadrate; 14, 31 - Lateralmost point of quadrate; 15, 32 - Posterior tip of pterygoid process; 16, 33 - Posterior point of quadrate; 17, 34 - Posterior tip of otooccipital; 18 - Posteriormost point on the curve of the occipital condyle. 
tails about specimens - locality coordinates, voucher numbers, sex, number of specimens and condition of syntopy with $P$. melisellensis, are given in the supplementary table (Table S1).

\section{Skull preparation and landmarks}

The skulls of $P$. muralis from Malo Starčevo island were prepared as dry skeletons - flesh was removed by dermestid beetles (Aleksić, 1997). The skulls of P. muralis from Malo Beško island, Zeta and Belgrade were cleared with trypsin and potassium hydroxide (Dingerkus and Uhler, 1977). All samples were stained with Alizarin Red S to better distinguish between skeletal elements and their articulations, and preserved in glycerol. Digital images of ventral skull were taken with Sony DSC F828 (resolution 8.0 MP; Sony Corp., Tokyo, Japan). Each skull was submerged in glycerol and placed in the centre of the optical field, with palate oriented parallel to the image plane. Camera setup and placement of the lens relative to the specimen $(3 \mathrm{~cm}$ from the skull) were kept constant to minimize image error related to distortion and parallax (Mullin and Taylor, 2002). The 34 landmarks (16 symmetric and 2 median) on the ventral skull were digitized (by A.U.) using TpsDig 2 software (Rohlf, 2008). The landmark configuration was based on previous studies on the lacertid lizard skull morphology (Ljubisavljević et al., 2010, 2011; Urošević et al., 2012, 2013) (Fig. 1). The chosen landmarks were present on all specimens and they sufficiently summarize the morphology of the ventral skull symmetric structures - contact points between bones, tips of processes, or the point of maximum curvature of structures (Bookstein, 1991).

\section{Statistical analyses}

To obtain information on ventral skull shape with differences related to size, position and orientation removed (Rohlf and Slice, 1990; Bookstein, 1996; Dryden and Mardia, 1998), we performed a Generalized Procrustes Analysis (GPA) which yields a matrix of Procrustes coordinates - shape variables which can be further used as input variables in any conventional statistical analysis (Zelditch et al., 2012). Shape analyses were done on the symmetric component of shape variation - the average of original and mirrored configurations of each specimen (Klingenberg et al., 2002). The set of shape variables was obtained using MorphoJ software (Klingenberg, 2011). We used centroid size (CS), the square root of the summed squared distances of each landmark from the centroid of the landmark configuration, as a geometric measure of the ventral skull size (Bookstein, 1991; Zelditch et al., 2012).

\section{Size and shape variation}

Since significant sexual dimorphism in skull size and shape was established in this species (Ljubisavljević et al., 2010), we did all our analyses on separated sexes. To assess differences in skull size between populations, we employed ANOVA with CS as the dependent variable and population as factor. To explore variation in skull shape, we employed MANOVA with the symmetric component of the shape variation as the dependent variables and population as factor. To assess effects of insularity and syntopy, and their interaction, on size, we employed ANOVA with $\mathrm{CS}$ as the dependent variable and insularity and syntopy as factors. For effects of insularity and syntopy on shape, as well as insularity - syntopy interaction, we used MANOVA with symmetric components of shape variation as the dependent variables and insularity and syntopy as factors.

The differences in size among populations were obtained by comparing mean CS values of each population.

To explore variation in ventral skull shape among populations and to visualize skull shape changes, we conducted a PCA analysis on the covariance matrix of the shape variables (symmetric component). The PCA analysis was performed using MorphoJ software (Klingenberg, 2011).

Mean shape configuration was calculated for each population (females and males separately). Procrustes distances were calculated between mean shapes and permutation test was performed to estimate statistical significance of divergence among populations. The Procrustes distances among populations and statistical significance were assessed using MorphoJ software (Klingenberg, 2011).

\section{Analysis of allometry and removing the effect of size}

Static allometry denotes size-related shape changes measured in different individuals at the same developmental stage within a population or species (Klingenberg, 1998; Shingleton, 2010). To assess the effect of size on shape within and among populations, we explored the size-related shape changes within populations by regressing the shape variables on CS, and 
Table 1. Effects of insularity and syntopy on ventral skull size.

\begin{tabular}{llrrrr}
\hline sex & effect & SS & df & F & p \\
\hline females & insularity & 410.68 & 1 & 219.83 & $<1.0 \times 10^{-4}$ \\
& syntopy & 25.03 & 1 & 13.4 & $4.8 \times 10^{-4}$ \\
& insularity $\times$ syntopy & 7.96 & 1 & 4.26 & $4.3 \times 10^{-2}$ \\
\multirow{2}{*}{ males } & insularity & 568.15 & 1 & 163.84 & $<1.0 \times 10^{-4}$ \\
& syntopy & 77.68 & 1 & 22.4 & $1.2 \times 10^{-5}$ \\
& insularity $\times$ syntopy & 43.34 & 1 & 12.5 & $7.5 \times 10^{-4}$ \\
\hline
\end{tabular}

Table 2. Effects of insularity and syntopy on ventral skull shape.

\begin{tabular}{lllllll}
\hline sex & effect & Wilks' $\lambda$ & effect df & error df & F & p \\
\hline females & insularity & 0.077 & 32 & 35 & 13 & $<1.0 \times 10^{-4}$ \\
& syntopy & 0.085 & 32 & 35 & 12 & $<1.0 \times 10^{-4}$ \\
& insularity $\times$ syntopy & 0.091 & 32 & 35 & 11 & $<1.0 \times 10^{-4}$ \\
males & insularity & 0.108 & 32 & 40 & 40 & 9 \\
& syntopy & 0.124 & 32 & 40 & 10 & $<1.0 \times 10^{-4}$ \\
& insularity $\times$ syntopy & 0.114 & 32 & & $<1.0 \times 10^{-4}$ \\
\hline
\end{tabular}

evaluated the similarity of static allometric trajectories among populations by comparing regression slopes. To check linearity we visually inspected the scatter plots of the regression scores. These preliminary analyses showed clear, linear relationship between shape changes and increase in size. To test if the allometric slopes differ among populations, we employed a multivariate analysis of covariance (MANCOVA) with the symmetric component of shape variation as dependent variables, population as factor and CS as covariate. Significant population $x$ CS interaction would indicate that size-dependent shape changes differ between populations.

In cases where multiple groups exhibit the same allometry, the multivariate regression can be done on pooled groups to assess the common allometric pattern (Klingenberg, 2011; Zelditch et al., 2012). We employed multivariate regression of the symmetric component of shape variation on CS to calculate the percentage of static allometry and statistical significance.

To explore variation between populations after correction for size, we carried out PCA on the covariance matrix of regression residuals. Multivariate regression and PCA analysis were performed using the MorphoJ program (Klingenberg, 2011).

\section{Results}

\section{Size and shape variation}

The differences in ventral skull size were statistically significant among populations, for each sex: ANOVA, $F=88.22, \mathrm{df}=3, \mathrm{p}<0.0001$ (females) and $F=75.81, \mathrm{df}=3$, $\mathrm{p}<0.0001$ (males). The effects of both insularity and

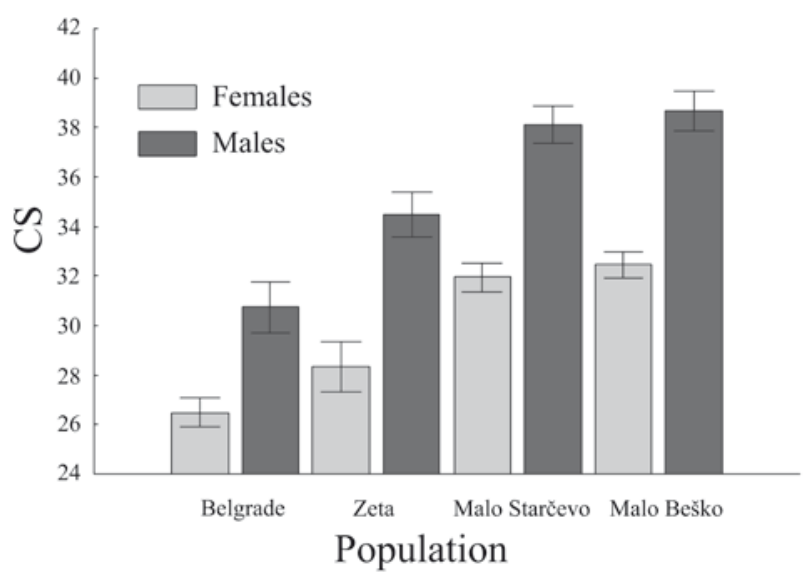

Fig. 2. Mean skull size (CS) values for females and males of all four studied populations, with $95 \%$ confidence intervals. 
Table 3. Interpopulation size and shape divergence (in Procrustes distances) for females (above the diagonal) and males (below the diagonal). Statistical significance of the Procrustes distances after the permutation test $(N=10000)$ is indicated by $*(\mathrm{p}<0.05)$.

\begin{tabular}{|c|c|c|c|c|}
\hline population & Belgrade & Zeta & Malo Starčevo & Malo Beško \\
\hline Belgrade & & $0.0233 *$ & $0.0271 *$ & $0.0303 *$ \\
\hline Zeta & $0.0287 *$ & & $0.0301 *$ & $0.0257 *$ \\
\hline Malo Starčevo & $0.0307 *$ & $0.0398 *$ & & $0.0239 *$ \\
\hline Malo Beško & $0.0319^{*}$ & $0.0266^{*}$ & $0.0346^{*}$ & \\
\hline
\end{tabular}

Table 4. Allometric shape changes between populations for each sex, tested by multivariate analysis of covariance (MANCOVA). CS - centroid size.

\begin{tabular}{llllcrrr}
\hline sex & effect & Wilks' $\lambda$ & effect df & error df & F & p \\
\hline female & population & 0.207 & 96 & 108.66 & 0.78 & 0.887 \\
& CS & 0.146 & 32 & 36 & 6.57 & $<1.0 \times 10^{-4}$ \\
& population $\times$ CS & 0.215 & 96 & 108.66 & 0.76 & 0.915 \\
male & population & & & & 0.372 \\
& CS & 0.109 & 96 & 93.69 & 1.07 & $1.0 \times 10^{-6}$ \\
& population $\times$ CS & 0.134 & 32 & 93.69 & 1.03 & 0.448 \\
\hline
\end{tabular}

syntopy on skull size were statistically significant with significant insularity $\times$ syntopy interaction (marginal in females) (Table 1). The specimens from the two islands were similar in skull size and clearly larger than those from mainland populations (Fig. 2).

The results of MANOVA showed statistically significant differences in skull shape among populations: Wilks' Lambda $=0.002176, F=8, \mathrm{p}<0.0001$ (females) and Wilks' Lambda $=0.001028, F=10, \mathrm{p}<0.0001$ (males). The variation in skull shape among populations was also influenced by both insularity and syntopy, and the insularity $\times$ syntopy interaction was significant (Table 2).

The position of the specimens in the morphospace defined by the first two axes obtained by PCA analysis of skull shape variables and visualisation of related skull shape changes are presented in Fig. 3. In females, the first two PC axes accounted for $45.04 \%$ of the total shape variation. The $\mathrm{PC} 1$ described the transition from insular to mainland populations. Females from insular populations Malo Starčevo and Malo Beško had proportionally reduced skull base, shortened quadrates, enlarged jaw adductor muscle chambers, elongated jaw-closing in-lever (distance from the posterior edge of the postorbital bar to the quadrate) and elongated rostrum, while females from Belgrade and Zeta (main- land populations) had enlarged skull base, elongated quadrates, reduced jaw adductor muscle chambers, shortened jaw-closing in-lever and shorter rostrum. The PC2 described shape differences between allotopic and syntopic populations. Individuals from syntopic populations Zeta (mainland) and Malo Beško (island) with reduced skull base, quadrates shifted laterally, reduced subocular foramina, enlarged jaw adductor muscle chambers, skull widened in the jugal region and shorter rostrum, separated from allotopic Belgrade (mainland) and Malo Starčevo (island) individuals with enlarged skull base, quadrates shifted medially, enlarged subocular foramina, reduced jaw adductor muscle chambers, skull narrowed in the jugal region and elongated rostrum (Fig. 3A).

The pattern observed in males was similar to the one observed in females (Fig. 3B). The first two PCs accounted for $51.15 \%$ of the total shape variation. The PC1 axis described changes in skull shape in island populations Malo Starčevo and Malo Beško, with medially shifted quadrates, narrower skull and elongated rostrum, comparing to mainland Belgrade and Zeta populations, with laterally shifted quadrates, wider skull and shortened rostrum. The PC2 axis described differences between allotopic and syntopic populations, from Malo Beško and Zeta individuals, with 

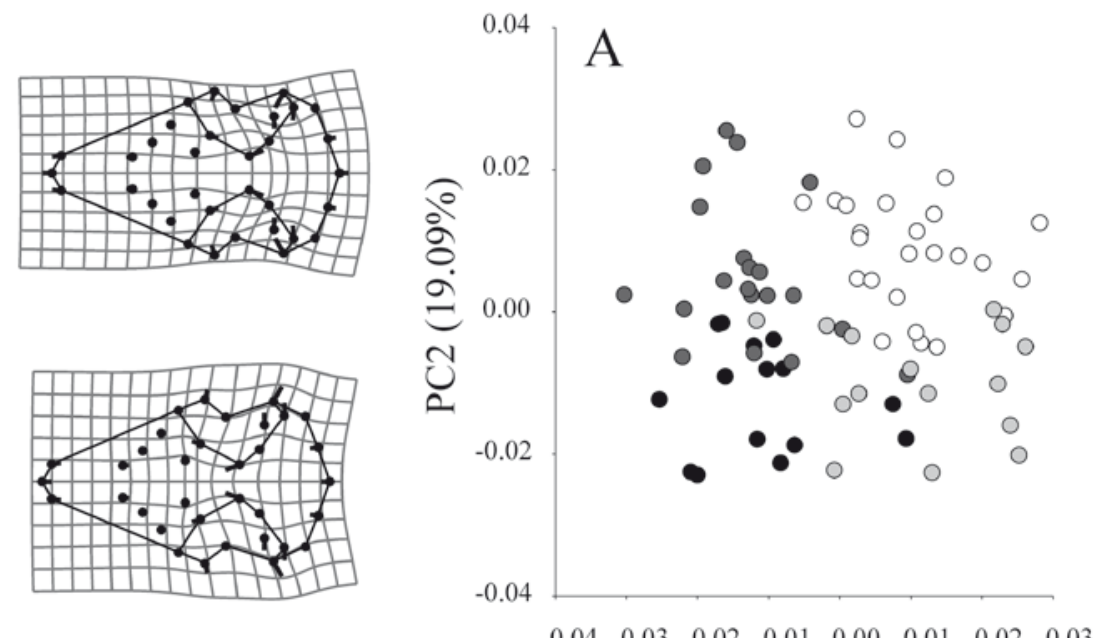

PC1 $(25.95 \%)$
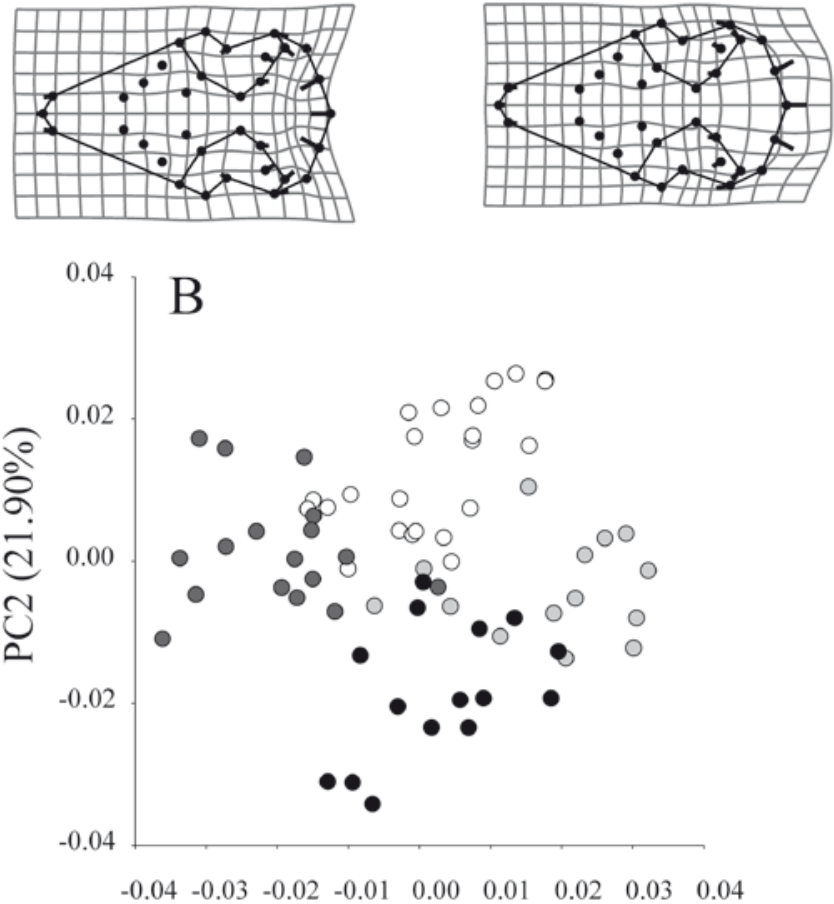

PC1 $(30.06 \%)$
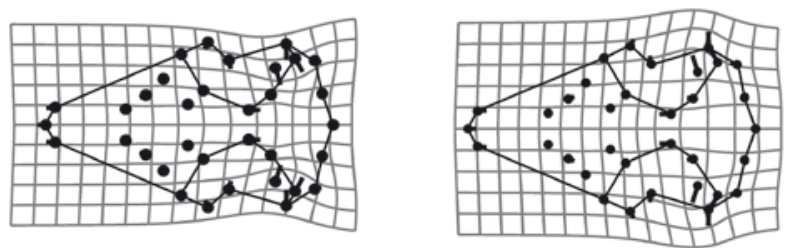

Fig. 3. The positions of the specimens from four populations of $P$. muralis in the morphospaces of the ventral skull shape defined by first two PC axes. Deformation grids illustrate shape changes associated with first two PC axes. The lines between landmarks 6, 7, 8, $10,11,12,14$ and 15 as well as $23,24,25,27,28,29,31$, and 32 define the jaw adductor muscle chambers. 
reduced skull base, shorter quadrates, wider crania, enlarged jaw adductor muscle chambers and reduced subocular foramina, to Malo Starčevo and Belgrade individuals, with enlarged skull base, longer quadrates, narrower crania, reduced jaw adductor muscle chambers and enlarged subocular foramina (Fig. 3B).

Interpopulation distances were higher for males than for females, and statistically significant in all cases $(p<0.0001)$. Females were clustering according to insularity, and continental populations were the most similar regarding to the ventral skull shape. In males, syntopic populations from Zeta and Malo Beško island clustered together (Table 3).

\section{Analysis of allometry and removing the effect of size}

The MANCOVA results (Table 4) indicated that populations have a common static allometric slope (population $\times$ CS interaction was insignificant). The results of multivariate regression of shape variables on CS revealed that $21.48 \%$ (females) and $18.90 \%$ (males) of shape variation could be explained by allometry. The regressions were statistically significant in both cases $(\mathrm{p}<0.0001)$.

The positions of individuals in the allometry-free morphospace (first two PC axes obtained on residual data set) are presented in Fig. 4. For females, the first two PCs accounted for $40.02 \%$ of allometry-free shape variation. Along the first axis specimens from Belgrade and Malo Starčevo (with elongated snouts and reduced jaw adductor muscle chambers), gradually separated from Malo Beško and Zeta animals (with shorter snouts, wider crania and enlarged jaw adductor muscle chambers). Most of the shape changes described by the second axis were related to within-population variation (Fig. 4A). For males, the first two PCs described $49.58 \%$ of the total non-allometric shape variation, with the same pattern as observed in females. Along the PC1 axis, Malo Beško and Zeta animals, with enlarged jaw adductor muscle chambers, wider crania and shorter and narrower snout, gradually separated from Belgrade and Malo Starčevo animals with reduced jaw adductor muscle chambers, narrower crania and elongated and wider rostrum. Along the PC2, there was some separation between animals from Malo Beško and Belgrade, with crania narrower in the jugal region, reduced skull base, enlarged jaw adductor muscle chambers and shortened quadrates, and animals from Malo Starčevo and Zeta, with crania wider in the jugal region, enlarged skull base, reduced jaw adductor muscle chambers and elongated quadrates (Fig. 4B).

\section{Discussion}

The studied populations of $P$. muralis in the Central Balkans significantly varied in skull size and skull shape. In the analysed samples, most of the variation in skull size was accounted for by the effect of insularity, which was expected (Crnobrnja et al., 1994; Castilla et al., 1998; Sá-Sousa et al., 2000; Arntzen and Sá-Sousa, 2007). The skull shape significantly varied among populations. Almost all observed variation in skull shape among populations is attributable to allometric shape changes. These shape changes described differences between smaller mainland and large insular populations. Non-allometric, size-independent shape changes suggested character displacement between populations of $P$. muralis, possibly due to interspecific competition with $P$. melisellensis.

Although some recent studies showed that allometry can be very variable in lizards and influenced by different ecological traits, mainly different habitat type or diet (Kaliontzopoulou et al., 2008; Ljubisavljević et al., 2011), our results indicated that, despite high variation in skull shape between populations, the static allometry in the ventral skull of $P . m u$ ralis was conserved, and the allometry related shape changes accounted for high percent of variation in skull shape within sample. Allometric shape changes among populations involved reduction of the skull base, posterior widening of the skull and elongation of the rostrum in the larger (insular) populations, which is largely similar to ontogenetic shape changes (Emerson and Bramble, 1993; Urošević et al., 2013).

Interestingly, when corrected for allometry, positions of specimens in non-allometric morphospace indicated that allotopic populations and populations which share habitat with $P$. melisellensis differ in skull shape. As noted before, the changes in ventral skull shape, especially jaw adductor muscle chamber, could be related to change in bite force, and skull biomechanics. The question is why the populations that share habitat with P. melisellensis differ in skull shape? The microhabitat shift between $P$. muralis and P. melisellensis in habitats where these species occur together is well documented (Arnold, 1987; Aleksić et al., 2009). Both species tend to be habitat generalists. However, in places where they co-occur, there is a 'specialization' of $P$. melisellensis for horizontal, vegetated and of $P$. muralis for vertical, rocky microhabitats (Arnold, 1987; Aleksić et al., 2009). In this case, ecological character displacement is a likely explanation for the observed morphological variation (Losos, 

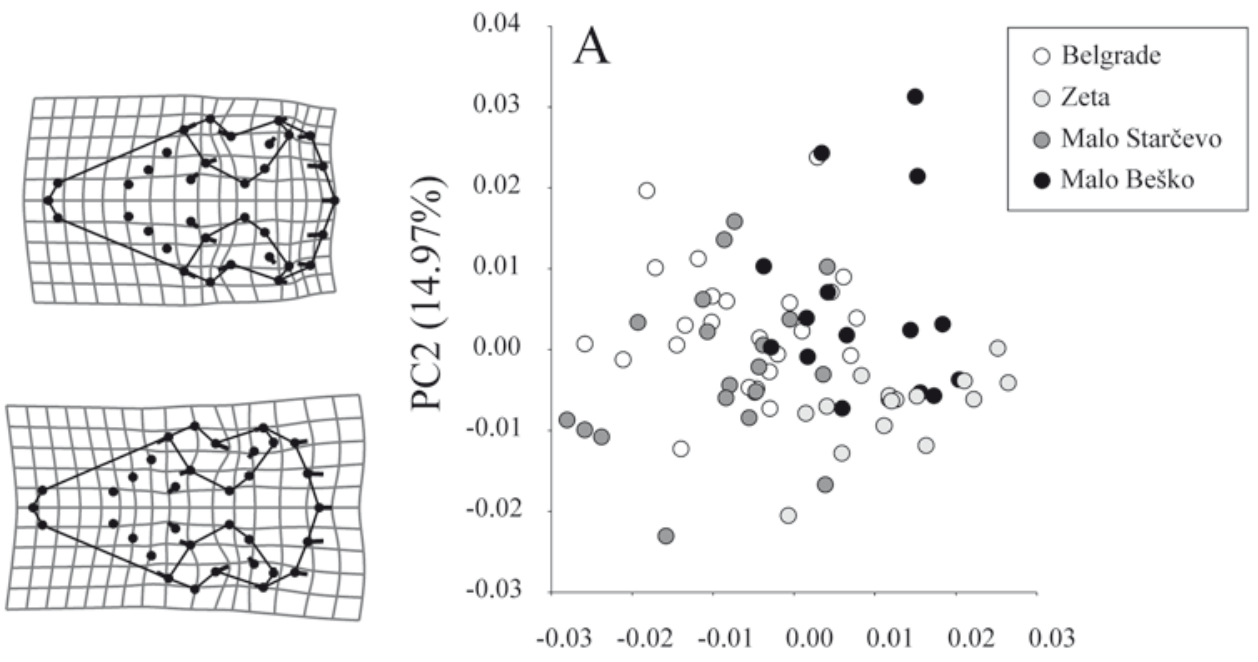

PC1 $(25.05 \%)$
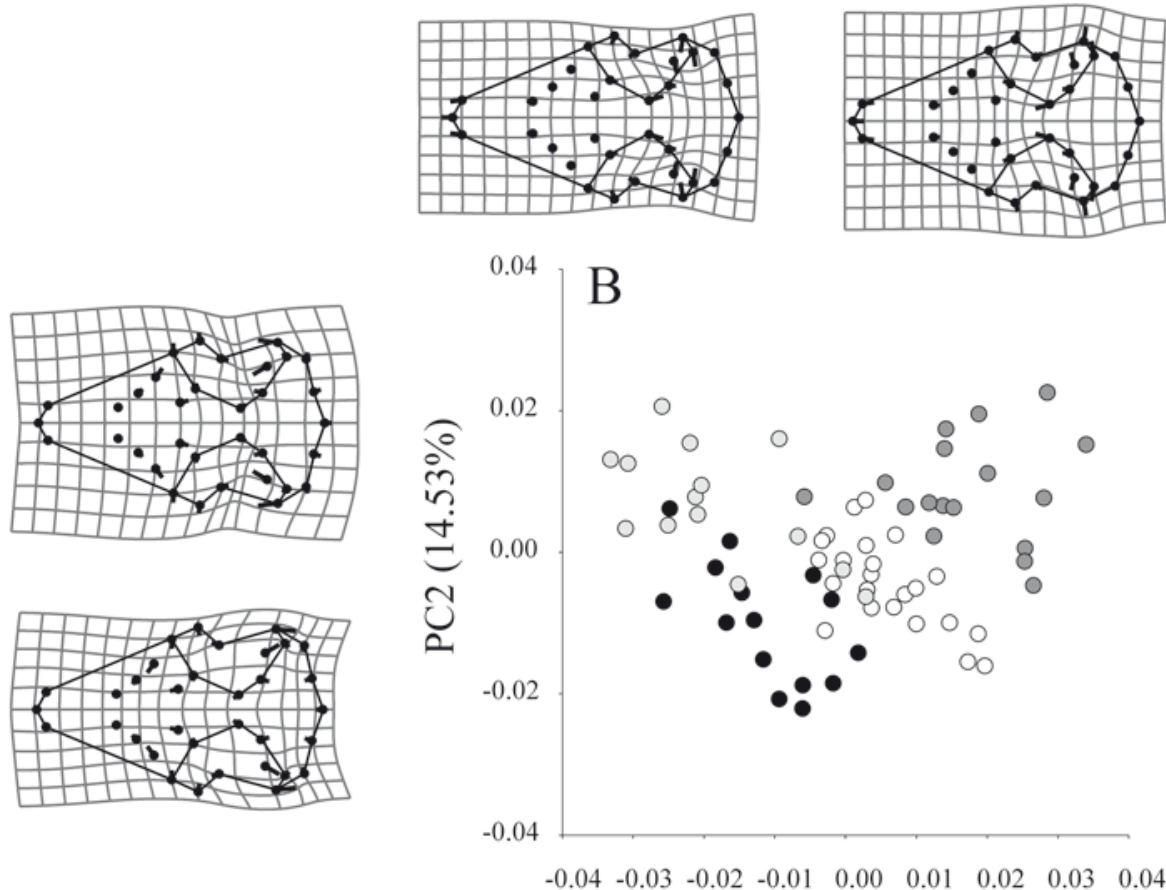

PC1 $(35.05 \%)$
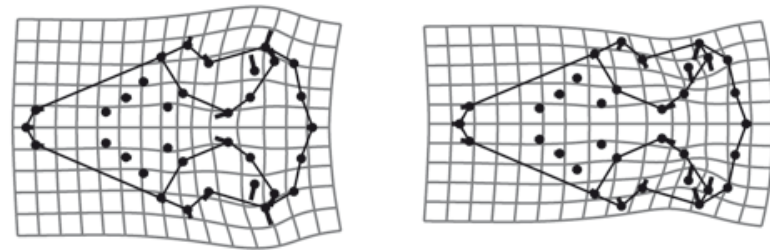

Fig. 4. The position of the specimens from four populations of $P$. muralis in the morphospaces of the ventral skull shape after the correction for size. Deformation grids illustrate shape changes associated with first two PC axes. The lines between landmarks $6,7,8,10$, $11,12,14$ and 15 as well as $23,24,25,27,28,29,31$, and 32 define the jaw adductor muscle chambers. 
2000; Corse et al., 2009; Stuart and Losos, 2013). Alternative explanations could be heterospecific aggression and trophic shift. Both $P$. muralis and $P$. melisellensis are aggressive, territorial species (Herrel et al., 2001; Sacchi et al., 2009; Lailvaux et al., 2012) and heterospecific male-male interactions between the two species could be expected in the microhabitat contact zones (Peiman and Robinson, 2010; Lailvaux et al., 2012). It was shown that aggressive male behaviour can have positive effect on bite force and enlargement of the jaw adductor muscles in lizards (Herrel et al., 2001, 2007). Also, cases of trophic shifts relating to insularity and the presence of competing lizard species have been observed in Podarcis lizards (Zuffi and Giannelli, 2013) and differences in diet also have implications on bite force potential and head morphology (Verwaijen et al., 2002).

However, we lack field observations of aggressive interaction between these two species or trophic shift among $P$. muralis populations in the Skadar Lake region, so these explanations remain hypothetical. The analysis of the size - independent shape changes revealed an intricate pattern of shape variation which can be influenced by various external factors, and further field studies are needed to correctly assess the sources of the complex intraspecific shape variation in Podarcis muralis.

\section{Acknowledgements}

We would like to thank Marco Zuffi and the anonymous reviewers for the constructive comments and suggestions which greatly improved the presentation of our data. We also thank Ivan Aleksić for providing detailed information on collection samples and Miloš L. Kalezić, Tanja Vukov, Milena Cvijanović and Nataša Tomašević Kolarov for helpful advices and suggestions on the early versions of the manuscript. This study was funded by the Serbian Ministry of Education, Science and Technological Development grant no. 173043.

\section{References}

Adams DC, Collyer ML. 2007. Analysis of character divergence along environmental gradients and other covariates. Evolution 61: 510-515.

Aleksić I. 1997. Age-related variability of morphological and anatomical traits in lizard populations Podarcis muralis (Laurenti, 1768) and Lacerta oxycephala (Dumeril and Bibron, 1839). PhD thesis Faculty of Biology: University of Belgrade.

Aleksić I, Ivanović A, Crnobrnja-Isailović J, Kalezić ML. 2009. Species and sex size/shape differences in the lacertid com- munity (Podarcis ssp. and Archaeolacerta sp.) from the Skadar Lake region (Montenegro). Italian Journal of Zoology 76: 43-52.

Arnold EN. 1987. Resource partitioning among lacertid lizards in southern Europe. Journal of Zoology 1: 739-782.

Arnold EN, Ovenden D. 2002. Field guide of reptiles and amphibians of Britain and Europe. Second Edition. London: Collins.

Arntzen JW, Sá-Sousa P. 2007. Morphological and genetical differentiation of lizards (Podarcis bocagei and P. hispani$c a$ ) in the Ria de Arosa archipelago (Galicia, Spain) resulting from vicariance and occasional dispersal. Pp. 365-401 in: Renema W, ed., Biogeography, Time and Place. Distributions, Barriers and Islands. Dordrecht: Springer.

Bejaković D, Aleksić I, Crnobrnja-Isailović J, Džukić G, Kalezić ML. 1996. Female reproductive dynamics and clutch traits in the common wall lizard (Podarcis muralis) from Skadar lake region, Montenegro. Revista Herpetologica Espania 10: 91-96.

Bookstein FL. 1991. Morphometric Tools for Landmark Data. Cambridge: Cambridge University Press.

Bookstein FL. 1996. Combining the tools of geometric morphometrics. Pp. 131-151 in: Marcus LF, Corti M, Loy A, Nayulor GJP, Slice DE, eds, Advances in Morphometrics. New York: Plenum Press.

Brown WL, Wilson EO. 1956. Character displacement. Systematic Zoology 5: 49-64.

Carlquist S. 1965. Island life. Garden City, New York: Natural History Press.

Case TJ. 1978. A general explanation for insular body size trends in terrestrial vertebrates. Ecology 59: 1-18.

Castilla AM, Fernández-Pedrosa V, Harris DJ, González A, Latorre A, Moya A. 1998. Mitochondrial DNA divergence suggests that Podarcis hispanica atrata (Squamata: Lacertidae) from the Columbretes islands merits specific distinction. Copeia 1998: 1037-1040.

Cirer AM, Martínez-Rica JP. 1990. The polymorphism of Podarcis pityusensis and its adaptative evolution in Mediterranean Isles. Herpetological Journal 1: 465-473.

Corse E, Costedoat C, Pech N, Chappaz R, Grey J, Gilles A. 2009. Trade-off between morphological convergence and opportunistic diet behaviour in fish hybrid zone. Frontiers in Zoology 6: 26.

Crnobrnja J, Džukić G, Aleksić I, Vujičić L, Avramov S. 1994. Distribution and genetic variation of the common wall lizard (Podarcis muralis, Lacertidae) populations from lake Skadar: Preliminary results. Bios (Macedonia, Greece) 2: 275-286.

Debat V, Bégin M, Legout H, David JR. 2003. Allometric and nonallometric components of Drosophila wing shape respond differently to developmental temperature. Evolution 57: 2773-2784.

Dingerkus G, Uhler LD. 1977. Enzyme clearing of alcian blue stained whole small vertebrates for demonstration of cartilage. Stain Technology 52: 229-232.

Džukić G. 1977. Medjusobno kompetitivno isključivanje Lacerta oxycephala i Lacerta muralis na ostrvima Skadarskog jezera. III simpozijum biosistematicara Jugoslavije: Novi Sad: 24-27 juna: Sadrzaji referata: 75-76. [in Serbian]

Dryden IL, Mardia KV. 1998. Statistical Shape Analysis. New York: Wiley.

Emerson SB, Bramble DM. 1993. Scaling, allometry and skull design. Pp. 384-421 in: Hanken J, Hall BK, eds, The Skull. 
Functional and Evolutionary Mechanisms, vol. 3. Chicago: The University of Chicago Press.

Foster JB. 1964. Evolution of mammals on islands. Nature 202: 234-235.

Gidaszewski NA, Baylac M, Klingenberg CP. 2009. Evolution of sexual dimorphism of wing shape in the Drosophila melanogaster subgroup. BMC Evolutionary Biology 9: 110.

Gould SJ. 1966. Allometry and size in ontogeny and phylogeny. Biological Review of the Cambridge Philosophical Society 41: 587-638.

Hallgrímsson B, Hall BK. 2005. Variation: A Central Concept in Biology. New York: Academic Press (Elsevier)

Herrel A, Van Damme R, Vanhooydonck B, De Vree F. 2001. The implications of bite performance to diet in two species of lacertid lizards. Canadian Journal of Zoology 79: 662670.

Herrel A, McBrayer LD, Larson PM. 2007. Functional basis for sexual differences in bite force in the lizard Anolis carolinensis. Biological Journal of the Linnean Society 91: 111-119.

Herrel A, Huyghe K, Vanhooydonck B, Backeljau T, Breugelmans K, Grbac I, Van Damme R, Irschick DJ. 2008. Rapid large-scale evolutionary divergence in morphology and performance associated with exploitation of a different dietary resource. PNAS 105: 4792-4795.

Kaliontzopoulou A, Carretero MA, Llorente GA. 2008. Head shape allometry and proximate causes of head sexual dimorphism in Podarcis lizards: joining linear and geometric morphometrics. Biological Journal of the Linnean Society 93: 111-124.

Klingenberg CP. 1996. Multivariate allometry. Pp. 23-49 in: Marcus LF, Corti M, Loy A, Naylor GJP, Slice DE, eds, Advances in Morphometrics. New York: Plenum Press.

Klingenberg CP. 1998. Heterochrony and allometry: the analysis of evolutionary change in ontogeny. Biological Reviews 73: 79-123.

Klingenberg CP. 2011. MorphoJ: an integrated software package for geometric morphometrics. Molecular Ecology Resources 11: 353-357.

Klingenberg CP, Barluenga M, Meyer A. 2002. Shape analysis of symmetric structures: quantifying variation among individuals and asymmetry. Evolution 56: 1909-1920.

Lailvaux SP, Huyghe K, Van Damme R. 2012. Why can't we all just get along? Interspecific aggression in resident and nonresident Podarcis melisellensis lizards. Journal of Zoology 288: 207-213.

Ljubisavljević K, Urošević A, Aleksić I, Ivanović A. 2010. Sexual dimorphism of skull shape in lacertid lizard species (Podarcis spp., Dalmatolacerta sp., Dinarolacerta sp.) revealed by geometric morphometrics. Zoology 113: 168-174.

Ljubisavljević K, Polović L, Urošević A, Ivanović A. 2011. Patterns of morphological variation in the skull and cephalic scales of the lacertid lizard Algyroides nigropunctatus. Herpetological Journal 21: 65-72.

Lomolino MV. 2005. Body size evolution in insular vertebrates: generality of the island rule. Journal of Biogeography 32: 1683-1699.

Losos JB. 2000. Ecological character displacement and the study of adaptation. Proceedings of The National Academy of Sciences of the United States of America 97: 5693-5695.

Meiri S. 2007. Size evolution in island lizards. Global Ecology and Biogeography 16: 702-708.
Meiri S, Dayan T, Simberloff D. 2006. The generality of the island rule re-examined. Journal of Biogeography 33: 15711577.

Meiri S, Cooper N, Purvis A. 2008. The island rule: made to be broken? Proceedings of the Royal Society B 275: 141-148.

Meiri S, Simberloff D, Dayan T. 2011. Community-wide character displacement in the presence of clines: a test of Holarctic weasel guilds. Journal of Animal Ecology 80: 824-834.

Mullin SK, Taylor PJ. 2002. The effects of parallax on geometric morphometric data. Computers in Biology and Medicine 32: 455-464.

Pearson D, Shine R, How R. 2002. Sex-specific niche partitioning and sexual size dimorphism in Australian pythons (Morelia spilota imbricata). Biological Journal of the Linnean Society 77: 113-125.

Peiman KS, Robinson BW. 2010. Ecology and evolution of resource-related heterospecific aggression. Quarterly Review of Biology 85: 133-158.

Pfennig DW, Wund MA, Snell-Rood EC, Cruickshank T, Schlichting CD, Moczek AP. 2010. Phenotypic plasticity's impacts on diversification and speciation. Trends in Ecology and Evolution 25: 459-467.

Pianka ER. 1973. The structure of lizard communities. Annual Review of Ecology and Systematics 4: 53-74.

Radovanović M.1951. Vodozemci i gmizavci naše zemlje. Beograd: Naučna knjiga. [in Serbian]

Rohlf FJ. 2008. TpsDig2. Version 2.12. Department of Ecology and Evolution. State University of New York, Stony Brook, NY. Available at http://life.bio.sunysb.edu/morph/. [accessed January 15, 2013]

Rohlf FJ, Slice D. 1990. Extensions of the Procrustes method for the optimal superimposition of landmarks. Systematic Zoology 39: 40-59.

Sacchi R, Pupin F, Gentilli A, Rubolini D, Scali S, Fasola M, Galeotti P. 2009. Male-male combats in a polymorphic lizard: residency and size, but not color, affect fighting rules and contest outcome. Aggressive Behavior 35: 274-283.

Sá-Sousa P, Almeida AP, Rosa HD, Vicente LA, Crespo EG. 2000. Genetic and morphological relationships of the Berlenga wall lizard (Podarcis bocagei berlengensis: Lacertidae). Journal of Zoological Systematics and Evolutionary Research 38: 95-102.

Schluter D. 2000. The ecology of adaptive radiation. Oxford: Oxford University Press.

Schoener TW. 1977. Competition and the niche. Pp. 35-136 in: Gans C, Tinkle DW, eds, Biology of the Reptilia: Ecology and behaviour. London: London Academic Press.

Shingleton A. 2010. Allometry: the study of biological scaling. Nature Education Knowledge 3: 2.

Singleton M, Rosenberger AL, Robinson C, O’Neill R. 2011. Allometric and metameric shape variation in Pan mandibular molars: A digital morphometric analysis. The Anatomical Record 294: 322-334.

Stanković S. 1976. Jezera sveta. Beograd: Mala biblioteka Srpskog geografskog drustva. [in Serbian]

Stuart YE, Losos JB. 2013. Ecological character displacement: glass half full or half empty? Trends in Ecology and Evolution 28: 402-408.

Urošević A, Ljubisavljević K, Jelić D, Ivanović A. 2012. Variation in the cranium shape of wall lizards (Podarcis spp.): 
effects of phylogenetic constraints, allometric constraints and ecology. Zoology 115: 207-216.

Urošević A, Ljubisavljević K, Ivanović A. 2013. Patterns of cranial ontogeny in lacertid lizards: morphological and allometric disparity. Journal of Evolutionary Biology 26: 399-415.

Van Valen, L. 1973. A new evolutionary law. Evolutionary Theory 1: 1-33.

Verwaijen D, Van Damme R, Herrel A. 2002. Relationships between head size, bite force, prey handling efficiency and diet in two sympatric lacertid lizards. Functional Ecology 16: $842-850$.
Zelditch ML, Swiderski DL, Sheets DH. 2012. Geometric Morphometrics for Biologists: A Primer. $2^{\text {nd }}$ edition. San Diego: Elsevier Academic Press.

Zuffi MAL, Giannelli C. 2013. Trophic niche and feeding biology of the Italian wall lizard, Podarcis siculus campestris (De Betta, 1857) along western Mediterranean coast. Acta Herpetologica 8: 35-39.

Received: 22 August 2013

Revised and accepted: 8 January 2014

Published online: 10 February 2014

Editor: J. van Rooijen

\section{On-line Supplementary Information (SI)}

S1. The Podarcis muralis specimens included in the study. Material is deposited in the Herpetological Collection of the Institute for Biological Research 'Siniša Stanković', University of Belgrade, Serbia. N - number of specimens per population. Syn - populations share habitat with P. melisellensis. 


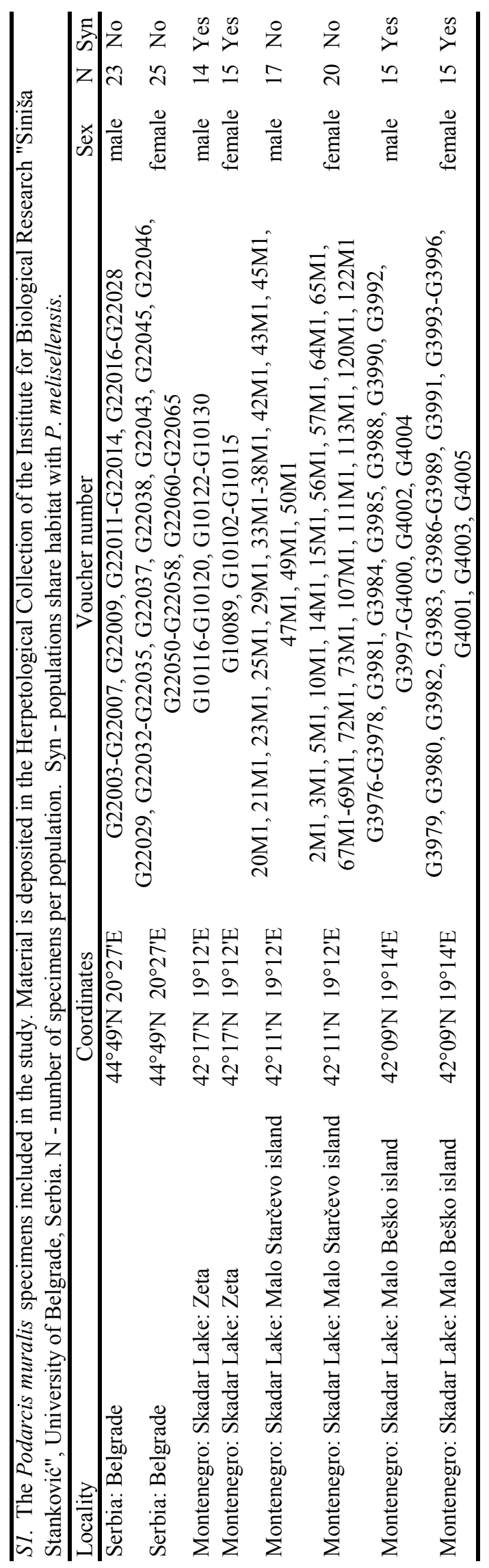

